\title{
Coping Strategy of Network Public Opinion on Emergencies
}

\author{
Na Wang ${ }^{1,2}$ * \\ ${ }^{1}$ Liaoning Shihua University, Northeastern University \\ Fushun, China \\ ${ }^{2}$ School of Mining Engineering, School of Marxism \\ Shenyang, China
}

\author{
Hanwen Fan \\ Liaoning Shihua University \\ Fushun China
}

\begin{abstract}
With the popularization and deep development of the Internet, it makes the public express their positions and emotions more convenient through the network after the occurrence of emergencies, which presents the trend of normalization, enlargement and complexity. In order to maintain the harmony and stability of the society and guide the network public opinion of sudden events to be developing, this paper starts with the current situation of network public opinion of unexpected events. Through investigation, interview and contrastive analysis, and finally puts forward the response to the emergencies from four aspects of the government, the public, the network and the emergency events. Put forward the strategies to deal with the public opinion of the emergency.
\end{abstract}

Keywords-Public sentiment of the internet; emergency response; strategy

\section{INTRODUCTION}

China has entered a new era of socialism with Chinese characteristics. With the rapid development of the Internet industry, "Internet media" has become the most popular way of information transmission. At present, china has entered an important period of social transformation; featuring profound changes in the economic system, dramatic changes in ideological concepts, and increasingly diversified interest demands. As a result, highlighted social conflicts have witnessed frequent occurrence of various emergencies, greatly challenged network security and social order. The high degree of network speech liberalization has increasingly influenced the network public opinion on society. Close attention has been paid to the trend of network public opinion, and the ability to continuously respond to it, as well as effective protection to its security will affect the public opinion or society's behavior. Therefore, there is a need to rationally analyze social emergencies triggered by varieties of contradictions, grasping the basic laws of network public opinion and strengthening its guidance to increase the pertinence and effectiveness of handling emergencies.

\section{The Development of Network Public Opinion In SUDDEN EVENTS}

Network public opinion is the unique product of China's political and social background and public opinion ecological environment. With regard to the concept of network public opinion, many scholars in our country have expounded it. In general, network public opinion refers to the network public opinion which is popular on the Internet in recent years, and is one of the forms of expression of public opinion. It is based on the network as the carrier, and is centered on specific events. The current situation of Internet public opinion in China is as follows:

\section{A. Public awareness is diversified and participation is gradually improving.}

With the development of information technology and the popularization of mobile Internet, the Internet is no longer a privilege of the rich, but has entered thousands of households and serves more people. In today's society, with the improvement of living standards and the diversity of people's attitudes, people have more time and energy to attention current news and participate in public opinion. People can log on to the Internet by computers and mobile phones at anytime and anywhere, to read the hot news and emergencies of the state and society in a timely manner. The public is both the manufacturer of the network public opinion and the conveyor. At present, "road side society" exists everywhere, everyone will be a reporter, and the participation of people in emergencies is gradually improving. [2]

\section{B. The government website has initially built, but it lacked effective communication with the public.}

Government official websites at all levels, as the first platform for government to publish information publicly, have basically been formed. Its main function is to perform functions and provide services for the society at all levels. Government information is open through government websites, and the public is interacted and communicated with the public. However, the update of the website information is not timely enough, the content of the website is not perfect, and the communication with the public is not smooth. Therefore, in the face of frequent network public opinion events in the society, most Government websites do not make use of the government website in time to make public clarification and guide public opinion in a right way.

\section{Social contradictions are increasing and public opinion crisis is coming.}

The network public opinion of the sudden incident is not suddenly happening. From its trigger mechanism, the network 
public opinion of the sudden events broke out on the basis of the continuous accumulation of social contradictions, which has certain inevitability, and the conflict of interests plays an important role in the mechanism of its occurrence. Our country is now in the key period of changing the way of economic development. In this period, people's life pressure has increased obviously, there are serious employment problems, and the gap between the rich and the poor is obvious, and so on. At this time, people are prone to anxiety, tension, confusion, dissatisfaction and other emotions. In cyberspace, there are a number of events every year, becoming a hot topic of network discussion, forming an increasingly prosperous network public opinion.[3]At present, the number of network emergencies is increasing, the types of events are constantly enriched, and the characters, phenomena and problems involved in the events are also expanding, and the network public opinion caused by the events also presents a trend of diversification, denseness and rapid development. Network public opinion presents the characteristics of spontaneity, complexity and one-sided features.

\section{Network public opinion data are massive, and emergencies are complicated.}

The popularity of the Internet products has a large number of hot events of concern every day. Internet citizens produce huge amounts of data when they publish personal views on the hot events. There is a wide variety of information, including text, audio, picture, digital, video and so on. The value density of network public opinion information is low and needs a filter. The emergencies are complicated in contents and time presses. There is no effective mechanism to deal with them.

\section{The Reasons for the DeVElopment of Network PUBLIC OPINION ON EMERGENCIES}

With the continuous development of the Internet, the number of Internet users in China is increasing, and the comprehensive quality of the Internet users is irregularity. In the face of the development of public opinion, the author labor the reasons .The network public opinion of sudden events shows the following effects:

\section{A. The "keyboard man" effect of network public opinion.}

The rapid development of the Internet has provided wide space for Internet citizens to freely make their speeches. A group of "keyboard heroes" who are keen to express their opinions freely on the Internet have appeared. And most of the "keyboard man" in the network, in the condition of anonymity and lack of rational thinking, the speech is often unrestrained mood to vent, the lack of a comprehensive understanding of the event, and easily lead to the malignant development of the situation.

\section{B. The double side effect of network public opinion.}

The network public opinion behind emergencies has a specific propagation process and a certain propagation rule. From the beginning of Internet citizens' attention to the rise and spread of attention, and then to the intervention of traditional media and government intervention and reflection, the level is relatively obvious. If the network public opinion is not handled properly, it will also bring negative influence on government, which will release the initiative of the government information, reduce the trust of the government, and the gap between the public and the government will increase the social instability factors and damage the public management system.

\section{The amplification effect of network public opinion.}

Because of the virtual nature of the Internet, most Internet citizens take part in the discussion of anonymity in unexpected events. Under the induction of irrational emotion, the discourses in reality have become unscrupulous in the network. Because of the lack of cognition and the lack of sense of responsibility, some Internet citizens even regard the network as a vented field. It is. Compared to the "keyboard man" effect, the amplification effect is mainly aimed at the expansion of the stakeholders and public opinion.

\section{The Coping Strategies of Network Public Opinion in EMERGENCY}

In the context of Internet public opinion, social emergencies will become more complicated. Only by accurately mastering the rule of Internet public opinion, and further thinking about how to treat network public opinion , have courage to accept the supervision of it, and form a benign interactive mechanism, can we correctly guide and response the Internet public opinion and properly handle emergencies. It is the fundamental requirement for the network public opinion to deal with the relationship between the main bodies of the public opinion, ensure the benign development of public opinion and protect the basic interests of the public opinion. To deal with the online emergencies on the public opinion scientifically, and effectively, following strategies should be taken.

\section{A. Raise the political consciousness of the whole people and set up a positive media view.}

As the network grows increasingly permeable to ordinary people, the Internet becomes a vital platform for netizen to fight for their interests, express emotions, criticize public events online .Therefore, we need to make objective, careful analysis and evaluation of the Internet public opinion, and can't blindly regard the online voice as the mainstream public opinion. Lag and passive have always been two big obstacles of emergency public opinion guide. The government departments should seriously analyze, set up positive media view and actively turn negative factors into positive factors, meet the reasonable demands, remove the bad emotions and nip public opinion events in the bud.[5]

\section{B. Broaden the channels of public opinion analysis and establish an online public opinion analysis system.}

The development of everything has its own evolution law. So does network public opinion of sudden events. Public opinion guidance and monitoring should also be in its own evolution, take corresponding measures to different stages, and give priority to deal it with guidance, control the scale between free speech and timely intervention. At the same time, we 
should use modern information technology to realize network public opinion monitoring, crisis early warning, control and guidance, establish a professional network public opinion analysis system to early warning, monitoring, analysis, a the Internet public opinion crisis. Secondly, a professional network supervision team should be set up to master and apply network technology skillfully, collect, sort out and master network public opinion information rapidly through high-tech means, carry out automatic analysis and live monitoring, quickly grasp the root of the problem in the process of network public opinion evolution, and provide an effective public information retrieval and analysis for our national security review.

\section{Strengthen the control of the source of public opinion, co- governance under the network.}

Network public opinion is the reflection of real social contradictions. At the same time, network public opinion affects the development direction of realistic contradictions. Collecting public opinion through network can make government departments understand the contradictions and conflicts of the real society and the appeals of the people. The online monitoring of the online public opinion and the offline disposal of the emergency is the two parts of the emergency response to the emergency, to solve the crisis at the source, online and offline collaborative work is need.

\section{Do a good job in emergency response strategy, grasp the direction of development of network public opinion.}

Timely and effective remedial measures should be taken for the development and change of Internet public opinion. The control system for the network public opinion relies on public opinion guide mechanism, information disclosure mechanism and strategies to refute slanders. The accuracy, timeliness and authoritativeness of publishing information have a great impact on the trend of Internet public opinion. At the same time, for the rumors that have been generated, we should timely dispel them and prevent them from continuing to ferment in the wrong direction.

\section{CONCLUSION}

In the era of high-speed the Internet development, in the face of unexpected events, original secure network space seems to have been in crisis and it has been tested under the influence of various factors. Starting from the present situation of the development of the network public opinion in China's emergency response, this paper makes an in-depth discussion and research on the causes of the current situation of the public opinion of the emergency, based on improving the political consciousness of people, setting up a positive view of the media, broadening the channel of public opinion analysis, establishing the network public opinion analysis system, and strengthening the control of the public opinion. In the four aspects of the development direction of network public opinion, the specific coping strategies of emergency network public opinion are put forward. The summary of these viewpoints has certain guiding significance and practical value for dealing with network public opinion in emergencies.[7]

\section{REFERENCES}

[1] Liu Qingsheng, Zhang Qiang, Zhang Yu. Research on coping strategies of network public opinion in University emergencies [J]. Journal of Jiangsu University of Science and Technology (SOCIAL SCIENCE EDITION), 2012 (3): 99-102.”In Chinese”

[2] Li Yunli. News disposal strategy and public opinion guidance mechanis $m$ of local government based on emergencies, [J]. speed reading journal, 2015 (11).”In Chinese”

[3] Fang Fu Jian. Research on the evolution of Internet public opinion in emergencies [D]. Huazhong University of Science and Technology, 2011.”In Chinese”

[4] Yuan Ye, LAN Yue Xin, Zhang Peng, et al. Research on coping mechanism of network public opinion in emergencies under the background of big data [J]. Journal of Armed Police College, 2017, 33 (1): 14-18."In Chinese"

[5] Zhao Zhao Shuang. Response to Internet public opinion on emergencies [J]. Journal of Changchun municipal Party school, 2016 (6): 9-11.”In Chinese"

[6] Wei Bing. The management strategy of police network public opin ion in the new media era: a case study of police network public opinion management in a prison [D]. Nanchang University, 2016.”In Chinese”

[7] Li Yanling, Li Gang. Internet public opinion analysis and coping strategies for emergencies under big data environment [J]. computer knowledge and technology, 2015, 11 (15): 14-15.”In Chinese 